AperTO - Archivio Istituzionale Open Access dell'Università di Torino

\title{
Atrial fibrillation ablation long-term ESC-EHRA EORP AFA LT registry: in-hospital and 1-year follow-up findings in Italy
}

\section{This is the author's manuscript}

Original Citation:

Availability:

This version is available http://hdl.handle.net/2318/1770006

since 2021-01-29T12:42:37Z

Published version:

DOI:10.2459/JCM.0000000000000999

Terms of use:

Open Access

Anyone can freely access the full text of works made available as "Open Access". Works made available under a Creative Commons license can be used according to the terms and conditions of said license. Use of all other works requires consent of the right holder (author or publisher) if not exempted from copyright protection by the applicable law. 


\title{
Atrial Fibrillation Ablation Long-Term
}

\author{
ESC EHRA EORP AFA LT registry
}

\section{In-hospital and 1-year follow-up findings in Italy}

\author{
Authors \\ Matteo Anselmino ${ }^{1}$, Andrea Ballatore ${ }^{1}$, Andrea Saglietto ${ }^{1}$, Giuseppe Stabile ${ }^{2}$, Roberto De \\ Ponti $^{3}$, Massimo Grimaldi ${ }^{4}$, Pietro Maria Giovanni Agricola ${ }^{5}$, Paolo Della Bella ${ }^{6}$, Massimo \\ Tritto $^{7}$, Carlo Pappone ${ }^{8}$, Leonardo Calò ${ }^{9}$, Maria Grazia Bongiorni ${ }^{10}$, Carina Blomström- \\ Lundqvist $^{11}$, Fiorenzo Gaita ${ }^{12}$, Gaetano Maria De Ferrari ${ }^{1}$ and the AFA LT registry italian \\ investigators group* \\ *Listed in Appendix 1
}

\section{Affiliations}

${ }^{1}$ Division of Cardiology, Department of Medical Sciences, "Città della Salute e della Scienza di Torino" Hospital, University of Turin, Italy

${ }^{2}$ Clinica Montevergine, Mercogliano (AV) and Casa di Cura San Michele, Maddaloni (CE), Italy

${ }^{3}$ Department of Heart and Vessels, Ospedale di Circolo-University of Insubria, Varese, Italy 
${ }^{4}$ Department of Cardiology, Ospedale Generale Regionale F. Muilli, Acquaviva delle Fonti, Italy ${ }^{5}$ Unità Operativa di Cardiologia, Casa di Cura Privata Piacenza, Piacenza, Italy

${ }^{6}$ Electrophysiology Laboratory and Arrhythmia Unit, San Raffaele Scientific Institute, Milan, Italy

${ }^{7}$ Istituto Clinico Humanitas Mater Domini, Castellanza (VA), Italy

${ }^{8}$ Arrhythmology Department, IRCCS Policlinico San Donato, San Donato Milanese, Italy

${ }^{9}$ Division of Cardiology, Policlinico Casilino, Rome, Italy

${ }^{10}$ Division of Cardiology and Arrhythmology, CardioThoracic and Vascular Department, University Hospital of Pisa, Pisa, Italy

${ }^{11}$ Department of Medical Science and Cardiology, Uppsala University, Uppsala, Sweden ${ }^{12}$ Cardiology Department, Clinica Pinna Pintor, 10129 Turin, Italy

\section{Corresponding author}

Prof. Fiorenzo Gaita

Cardiology Department, Clinica Pinna Pintor, 10129 Turin, Italy

e-mail: fiorenzo.gaita@gmail.com

(+39) 011-5802100 


\begin{abstract}
Aim: To report the Italian data deriving from the ESC-EORP Atrial Fibrillation Ablation Long-Term (AFA LT) registry.

Methods and results: Ten Italian centers enrolled up to 50 consecutive patients undergoing AF ablation. Of 318 patients included 5 (1.6\%) did not undergo catheter ablation, 1 had ablation partially done and 62 were lost at 1-year follow-up. Women were less represented $(23.6 \%)$ and the median age was 60.0 years. 195 patients $(62.3 \%)$ suffered paroxysmal AF, whereas only 9 (2.9\%) had long-standing persistent AF. Most Italian patients $(92.3 \%)$ were symptomatic but suffering less symptomatic events than patients enrolled in other countries (median of 2 events in the month preceding the ablation vs. 3 , respectively; $\mathrm{p}<0.0001)$. The main finding of the study is that the success rate at 1 -year, with and without antiarrhythmic drugs, was $76.4 \%$, consistent with other participating countries $(73.4 \%)$. This result was obtained however with a significantly lower prevalence of 1 -year adverse events $(7.3 \%$ vs. $16.6 \%, \mathrm{p}<0.0001)$. Procedure duration and fluoroscopy total time resulted shorter in Italy ( 145 vs. $160, p=0.0005$, and 16.9 vs. 20.0 minutes, $\mathrm{p}=0.0018$, respectively); however, radiation dose per body surface area was greater $(37.5$ vs. $26.0 \mathrm{mGy} / \mathrm{cm} 2, \mathrm{p}=0.0022)$.
\end{abstract}

Conclusion: The demographic characteristics of patients undergoing AF ablation are similar to those reported in other countries. The success rate in Italy is consistent with other countries, whereas the complications rate is lower.

Key words: atrial fibrillation, outcome, complications, radiation use, registry, Italy 


\section{Introduction}

Atrial fibrillation (AF) affects $2.04 \%$ of the Italian population[1] and represents the most common sustained tachyarrhythmia worldwide[2]. Its prevalence increases with age, as, according to the recent FAI project[3], 8.1\% (9.1\% in men and 7.3\% in women) of patients over 65 years of age are affected. Moreover, it has been estimated that, in Italy, by 2060 about 1'892'000 people over 65 years of age will be affected by the arrhythmia, in contrast with the estimated 1'081'000 by 2016[3]. AF has a severe impact both on cardiovascular events[4] and quality of life[5], being associated with an increased risk of dementia[6,7], stroke[8], systemic thromboembolic events[9], mortality and sudden cardiac death[10].

Either in patients who remain symptomatic despite antiarrhythmic drugs, or as first line approach in selected patients, pulmonary veins isolation via catheter ablation is a widely used approach for the treatment of AF[11]. For this reason, in 2012, the European Society of Cardiology (ESC) and European Heart Rhythm Association (EHRA) promoted a multicentre, prospective, observational registry to collect a large dataset on AF ablation in European and Mediterranean countries.

The ESC-EORP AF ablation long-term registry[12] provides a real-world snapshot of the management of patients undergoing AF ablation, as it allows to monitor indication, efficacy and complication rates of AF ablation in common practice. Its observational design, in addition, allows describing AF clinical management prior to the ablation procedure, highlighting improvable critical issues and guiding future research towards newer and more effective solutions. 
We hereby report the Italian data from the ESC-EORP AF ablation long-term registry, including in-hospital and 1-year follow-up.

\section{Methods}

The ESC-EORP AF ablation long-term registry has been previously described [12]. Briefly, in Italy, enrollment started in April 2012 and terminated in April 2015. Data collection was concomitant with enrollment and the study terminated 1 year after the last enrolled patient's AF ablation.. All centres with an electrophysiological laboratory performing AF ablation were invited to enroll all (with a maximum limit of 50) consecutive patients undergoing the procedure. No exclusion criteria were imposed, except for refusal to sign informed consent. Data were collected at enrollment time, during the procedure and hospitalization and at 12-months follow-up. Collected data included demographics and anamnestic information of patients, procedural and post-procedural data, and information on clinical course and medications during follow-up. Definitions of

paroxysmal, persistent and long-standing persistent AF followed 2010 ESC AF guidelines.

Definition of lone AF and AF recurrences have been specified elsewhere [12].

\section{Statistical analyses}

Continuous variables were reported as median and interquartile range (IQR). Categorical variables were reported as percentages. Kruskal-Wallis test was used to compare continuous variables among groups. Pearson's chi-squared and Fisher's exact test were used for among-groups comparison for categorical variables, the latter if the expected count for any cell was $<5$. Wilcoxon signed-rank test was used to detect intragroup 
differences before and after ablation procedure. Kaplan-Meier curves were built for time to first recurrence and comparison among groups was performed using log-rank test. P values $<0.05$ were considered statistically significant.

\section{Results}

Ten Italian centers participated in data collection. Of 318 patients included, $5(1.6 \%)$ did not undergo catheter ablation and 1 had ablation partially done. No patients died during the in-hospital phase. Of the 313 patients discharged after the procedure, 62 were lost at follow-up. (Fig. 1)

Patients' demographic characteristics are reported in Table S1 (Supplementary material). Median age was 60.0 years (IQR 54.0 - 66.0). 195 patients (62.3\%) suffered paroxysmal AF, whereas only 9 (2.9\%) had long-standing persistent AF. Women were less represented (23.6\%). The two most common cardiovascular risk factors were hypertension and hypercholesterolemia, affecting $61.1 \%$ and $32.5 \%$ of patients, respectively. Hypertension was also the most common underlying disorder, either as hypertensive cardiomyopathy ( $66.2 \%$ of patients without lone AF or hypertension without cardiomyopathy) or as hypertension in the absence of hypertensive cardiomyopathy (15.8\%). Lone AF was detected in $31 \%$ of the cases. Ischemic thromboembolic events had occurred in $6.4 \%$. The median number of $\mathrm{AF}$ episodes the month before enrollment was 2.0 (IQR 1.0 - 4.0): the majority of patients experienced palpitations, fatigue and/or dyspnoea $(87.8 \%, 37.8 \%$ and $32.3 \%$ respectively); $14.9 \%$ complained generic weakness and $4.5 \%$ suffered syncope. 
Overall, based on symptoms, more than nine out of ten patients were classified as EHRA score $2(76.9 \%)$ or $3(13.8 \%)$, whereas only $7.7 \%$ were asymptomatic.

Table 1 shows the comparison of baseline clinical characteristics between Italy and the other participating countries. The Italian population included a lower percentage of women $(\mathrm{p}=0.0010)$, whereas an increased percentage of Caucasian patients $(\mathrm{p}<0.0001)$ was found. Obesity $(\mathrm{BMI}>30 \mathrm{~kg} / \mathrm{m} 2)$, and former smoking were less prevalent in Italy, whereas hypertension was more diffused. Symptoms were assessed, both in terms of severity (EHRA score) and quality: in this respect, Italian patients experienced less symptomatic episodes $(\mathrm{p}<0.0001)$. Noticeable differences were present in terms of the underlying AF mechanism (with a greater portion of cases accountable to hypertensive cardiomyopathy, $\mathrm{p}<0.0001$, and fewer to coronary artery disease, $\mathrm{p}=$ 0.0063, chronic heart failure, $\mathrm{p}<0.0001$, and hypertension without known hypertensive cardiomyopathy, $\mathrm{p}<0.0001$ ) and AF precipitating factors (fewer episodes due to physical exercise, $\mathrm{p}<0.0001$, or alcohol abuse, $\mathrm{p}=0.0003$, respectively).

With regard to clinical management, in Italy, a larger portion of patients underwent cardioversion $(\mathrm{p}=0.0176)$ and antiarrhythmic drug trial $(\mathrm{p}=0.0279)$. A greater percentage of patients were administered flecainide and disopyramide, whereas fewer were under class III agents (amiodarone, dronedarone and sotalol) and propafenone. Eventually reasons of referral for AF ablation, classified as in the 2010 ESC AF guidelines, emerged as slightly different: in Italy, a greater portion of patients performed the procedure for sinus rhythm maintenance $(\mathrm{p}=0.0223)$ and fewer for symptoms $(\mathrm{p}=$ 
$0.0374)$, quality of life improvement $(\mathrm{p}<0.0001)$ or desire to discontinue drugs $(\mathrm{p}=$ $0.0379)$.

\section{Intraprocedural details}

Table S2 (Supplementary material) reports the technical characteristics of the procedure in Italy. Comparison of procedural details between Italy and the other enrolling countries is, instead, reported in Table 2. The use of rotational angiography for 3D reconstruction is more common in Italy, whereas circular mapping catheters are more commonly used in other countries. In Italy image fusion with pre-acquired cardiac magnetic resonance images is more commonly performed $(\mathrm{p}<0.0001)$. On the other hand, CT scan images integration is less performed $(\mathrm{p}<0.0001)$. Of note in Italy a lower percentage of procedures are performed with general anesthesia $(\mathrm{p}<0.0001)$. With regard to source of energy used, cryoablation is less diffused in Italy $(\mathrm{p}<0.0001)$ compared to other countries, in favor of radiofrequency with open irrigation $(\mathrm{p}<0.0001)$. Procedure duration $(\mathrm{p}=0.0005)$ and fluoroscopy total time $(\mathrm{p}=0.0018)$ are shorter in Italy, however radiation dose per body surface area appears greater $(\mathrm{p}=0.0022)$.

With regard to intraprocedural outcomes of efficacy, in Italy, PV entrance block was achieved in a greater portion of patients in the left superior and both right pulmonary veins. In addition, a greater portion of patients underwent mitral isthmus $(p=0.0354)$ and posterior line $(\mathrm{p}<0.0001)$ ablation, as well as elimination of fractionated electrograms ( $\mathrm{p}$ $<0.0001)$.

\section{Adverse events}

Adverse events associated with AF catheter ablation in Italy and the other participating countries are reported in Table S3 (Supplementary material) and Table 3, respectively. In 
Italian practice, the overall prevalence of adverse events, occurring both in-hospital and at 1-year follow-up, was $7.3 \%$.

Compared to other countries Italian, patients experienced less adverse events $(p<0.0001)$ and, more specifically, less cardiovascular complications $(p=0.0007)$.

\section{Success rate}

Overall success rate in Italy (Table S4, Supplementary material) was 76.4\%, with higher freedom from $\mathrm{AF}$ in the paroxysmal forms of the arrhythmia $(80.0 \% \mathrm{vs} .70 .6 \%$ and $66.7 \%$ for persistent and long-standing persistent AF, respectively). These results, as well as time to first recurrence are consistent with those obtained in the other enrolling countries (Table 4 and Figure 2). The impact of catheter ablation on symptoms severity is also reported in Figure 3a and Table S5 (Supplementary material).

Drugs assumption data is reported in Figure S1 (Supplementary material), at admission, discharge, before 12-months visit, and after 1-year follow-up. The major changes in drug treatment before and after the catheter ablation regard anticoagulant therapy, antiplatelet agents, antiarrhythmic and rate control drugs. The use of amiodarone (24\% and $12 \%$ at baseline and 1-year follow-up, respectively), dronedarone $(2 \%$ and $<1 \%$ at baseline and 1-year follow-up, respectively), flecainide (28\% and $18 \%$ at baseline and 1 -year follow-up, respectively) and digoxin $(3 \%$ and $<1 \%$ at baseline and 1 -year followup, respectively) was progressively reduced following AF ablation. At discharge more patients were administered VKA and LMWH compared to admission ( $76 \%$ vs. $60 \%$ for VKA and $37 \%$ vs. $23 \%$ for LMWH), however in a large portion of patients the treatment was discontinued during follow-up (32\% and none at 1-year follow-up for VKA and 
LMWH, respectively). The reduction in use of anticoagulation therapy was equally distributed in patients with different CHA2DS2-VASc scores and was maintained during follow-up before and after 12-months visit (Figure 3b).

\section{Discussion}

Several clinical studies have thoroughly assessed AF management, laying the basis for the current guidelines and recommendations [11]. Nevertheless, a "real life" registry, focusing on a general, unselected population, holds the potential to describe tendencies among categories/groups or even Countries that have not emerged yet. The utility of a National survey stems from the fact that many recent studies may not be representative of the national territory, as they focus on a singular ablation technique or on patients with a certain geographical origin, implying differences in environmental risk factors, genetic predisposition and comorbidities[13-16]. Moreover, data derived from clinical studies may relate to adoption of specific strategies in AF management and/or indication to catheter ablation. In fact, National surveys, focusing on AF epidemiology as the FAI [3] are available, whereas similar data on $\mathrm{AF}$ ablation are poor. Moreover, analysis of data from all participating countries allows regional comparisons, providing useful insights to national and supranational health organizations to trace politics in order to improve treatments and obtain equal health standards. In this prospective the main finding of the present analysis is that Tthe vast majority of AF ablations follow 2010 ESC guidelines recommendations, and, despite the data on success may be influenced by the lack of a standardized electrographic follow-up, as clearly stated in the original publication[12], the ablation success rate and clinical effects on symptoms 
in Italy are adequate and consistent with those reported in the other participating countries and in previously published RCTs $[17,18]$. However this outcome is obtained exposing patients to a minor rate of adverse events. Speculations on this aspect are difficult, present data, in any case, confirm a previous Italian registry[19]Lack of uniformity in data collection and under reporting may play a role, at least partially, in the difference detected; however specific cardiovascular complications (Table 3), attention towards which is the greatest during, at least, hospitalization, are statistically lower suggesting that an effective difference might exists. One of the reasons underlying this discrepancy may, indeed, be a more extensive use of image integration in Italy

Of note, the increased use of adjunctive ablation is not accompanied with an improved outcome; this could suggest that PVI is sufficient to achieve the desired clinical benefit. However, this finding can be driven by the fact that most of the enrolled patients had paroxysmal AF; from a single case perspective adjunctive ablation may still be useful in selected patients with persistent AF or history of atypical atrial flutter.

Interesting data emerge on oral anticoagulants prescription. More than $50 \%$ of the patients with a CHA2DS2-VASc score of 0 are prescribed anticoagulants before AF ablation and, despite a reduction, $35.2 \%$ still assume them after the procedure. On the other hand, among patients with a CHA2DS2-VASc score $>=2,17.6 \%$ were not on anticoagulation before the procedure. This percentage further increased at 12-month visit, most probably due to sinus rhythm recording, despite no clear evidences about the safety of this conduct are, to date, available[20,21]. Finally, ASA, although not recommended, is 
assumed by more than $10 \%$ of patients, and, despite a temporary reduction at discharge after the procedure, this percentage is confirmed during follow-up, suggesting that education programs aimed at improving Physicians' adherence to guidelines recommendations should be encouraged and pursued.

Concerning procedural characteristics, it must be taken into account that due to the recent years technology improvement, actual data may slightly differ from the hereby reported. As an example, cryoballoon ablation likely increased [22] after publication of the FIRE and ICE trial[23]. Given this, the minor use of cryoablation (usually performed under radiological guidance), along with a more diffused imagei integration in Italy, probably explain the shorter fluoroscopy time compared to the other countries. Counter intuitively, absorbed radiation dose per square centimeter of body surface area is greater in Italy. Caution should be exercised when interpreting these data: firstly there may have been no uniformity among centers in the collection of data; secondly this difference could stem from the more extensive use of rotational angiography, greater recourse to adjunctive ablation, more frequent cavotricuspid isthmus ablation, or poor implementation of new generation $\mathrm{x}$ ray machines and under utilization of techniques to optimize radiation use[24]. In any case, real-world data on this subject are fundamental: ionizing radiation represents an important caveat and needs to be considered for both patients and medical staff's safety. Monitoring of the implementation of near-to-zero x ray ablation approaches is needed [25]. 
Finally, it must be taken into account during the decision path towards referral for AF catheter ablation that the adverse event rate at 1 year is not marginal, being in Italy, albeit roughly half than in other Countries, $7.3 \%$.

\section{Limitations}

This study presents some limitations. First the design of the study, limited to 1-year follow-up. The analysis was conducted on aggregated data, not enabling considerations on subgroups characteristics and, for example, to define whether a more extensive ablation could be useful in selected patients. Since the survey included 318 patients, statistical under powering may be taken into account; in particular the discrepancy concerning complication rates may arise from the fact that generally very rare adverse events might not have been, by chance, observed in Italian centers. Finally, due to the rapid advances in the field, data may not be representative of the current situation.

\section{Conclusion}

We have reported the ESC-EHRA AF long-term registry findings on AF catheter ablation in Italy. Overall success rate in Italy is consistent with that achieved in other participating countries, whereas 1-year complications rate is significantly lower. Finally, in Italy, despite lower procedure and fluoroscopy times, patients undergoing AF ablation are exposed to a greater amount of ionizing radiation, calling for action toward improving this aspect. 


\section{Acknowledgments}

EORP Oversight Committee, Registry Executive Committee and Steering Committee of the EURObservational Research Program (EORP). Data collection was conducted by the EORP department from the ESC by Elin Folkesson Lefrancq as Project Officer, Viviane Missiamenou as Data Manager. Statistical analyses were performed by Cécile Laroche. Overall activities were coordinated and supervised by Dr. Aldo P. Maggioni (EORP Scientific Coordinator). All investigators listed in the Supplementary Appendix 1.

\section{Funding}

Since the start of EORP, the following companies have supported the program: Abbott Vascular Int. (2011-2021), Amgen Cardiovascular (2009-2018), AstraZeneca (2014-2021), Bayer AG (2009-2018), Boehringer Ingelheim (2009-2019), Boston Scientific (2009-2012), The Bristol Myers Squibb and Pfizer Alliance (2011-2019), Daiichi Sankyo Europe GmbH (2011-2020), The Alliance Daiichi Sankyo Europe GmbH and Eli Lilly and Company (2014-2017), Edwards (2016-2019), Gedeon Richter Plc. (2014-2016), Menarini Int. Op. (2009-2012), MSD-Merck \& Co. (2011-2014), Novartis Pharma AG (2014-2020), ResMed (2014-2016), Sanofi (2009-2011), Servier (2009-2021), Vifor (2019-2022).

\section{Conflict of interest}

MA is consultant for Biosense Webster and has received educational grants from Abbott; RDP has received lectures fees from Biosense Webster and Biotronik MG holds a patent agreement with Biosense Webster not related to this paper. 
AB, AS, GS, PMGA, PDB, MT, CP, LC, MGB, CBL, FG and GMDF declare no conflict of interest. 


\section{References}

1. Zoni-Berisso M, Filippi A, Landolina M, Brignoli O, D’Ambrosio G, Maglia G, Grimaldi M, Ermini G. 2013 Frequency, Patient Characteristics, Treatment Strategies, and Resource Usage of Atrial Fibrillation (from the Italian Survey of Atrial Fibrillation Management [ISAF] Study). Am. J. Cardiol. 111, 705-711. (doi:10.1016/j.amjcard.2012.11.026)

2. Andrade J, Khairy P, Dobrev D, Nattel S. 2014 The clinical profile and pathophysiology of atrial fibrillation: Relationships among clinical features, epidemiology, and mechanisms. Circ. Res. (doi:10.1161/CIRCRESAHA.114.303211)

3. Di Carlo A et al. 2019 Prevalence of atrial fibrillation in the Italian elderly population and projections from 2020 to 2060 for Italy and the European Union: the FAI Project. EP Eur. 21, 1468-1475. (doi:10.1093/europace/euz141)

4. Benjamin EJ, Wolf PA, D’Agostino RB, Silbershatz H, Kannel WB, Levy D. 1998 Impact of Atrial Fibrillation on the Risk of Death. Circulation 98, 946-952.

(doi:10.1161/01.CIR.98.10.946)

5. Thrall G, Lane D, Carroll D, Lip GYH. 2006 Quality of Life in Patients with Atrial Fibrillation: A Systematic Review. Am. J. Med. 119, 448.e1-448.e19. (doi:10.1016/j.amjmed.2005.10.057)

6. Kalantarian S, Stern TA, Mansour M, Ruskin JN. 2013 Cognitive Impairment Associated With Atrial Fibrillation: A Meta-analysis. Ann. Intern. Med. 158, 338. (doi:10.7326/00034819-158-5-201303050-00007)

7. Saglietto A, Matta M, Gaita F, Jacobs V, Bunch TJ, Anselmino M. 2019 Strokeindependent contribution of atrial fibrillation to dementia: a meta-analysis. Open Hear. 6, 
e000984. (doi:10.1136/openhrt-2018-000984)

8. Wolf PA, Abbott RD, Kannel WB. 1991 Atrial fibrillation as an independent risk factor for stroke: the Framingham Study. Stroke 22, 983-988. (doi:10.1161/01.STR.22.8.983)

9. Bekwelem W et al. 2015 Extracranial Systemic Embolic Events in Patients With Nonvalvular Atrial Fibrillation. Circulation 132, 796-803. (doi:10.1161/CIRCULATIONAHA.114.013243)

10. Odutayo A, Wong CX, Hsiao AJ, Hopewell S, Altman DG, Emdin CA. 2016 Atrial fibrillation and risks of cardiovascular disease, renal disease, and death: systematic review and meta-analysis. BMJ 354, i4482. (doi:10.1136/bmj.i4482)

11. Kirchhof P et al. 20162016 ESC Guidelines for the management of atrial fibrillation developed in collaboration with EACTS. Eur. J. Cardiothorac. Surg. (doi:10.1093/ejcts/ezw313)

12. Arbelo E et al. 2017 Contemporary management of patients undergoing atrial fibrillation ablation: in-hospital and 1-year follow-up findings from the ESC-EHRA atrial fibrillation ablation long-term registry. Eur. Heart J. 38, ehw564. (doi:10.1093/eurheartj/ehw564)

13. Tondo C et al. 2018 Pulmonary vein isolation cryoablation for patients with persistent and long-standing persistent atrial fibrillation: Clinical outcomes from the real-world multicenter observational project. Heart Rhythm 15, 363-368.

(doi:10.1016/j.hrthm.2017.10.038)

14. Forleo GB et al. 2013 Catheter ablation of atrial fibrillation guided by a 3D electroanatomical mapping system: a 2-year follow-up study from the Italian Registry On NavX Atrial Fibrillation ablation procedures (IRON-AF). J. Interv. Card. Electrophysiol. 
37, 87-95. (doi:10.1007/s10840-012-9772-4)

15. Gaita F, Scaglione M, Battaglia A, Matta M, Gallo C, Galatà M, Caponi D, Di Donna P, Anselmino M. 2018 Very long-term outcome following transcatheter ablation of atrial fibrillation. Are results maintained after 10 years of follow up? EP Eur. 20, 443-450. (doi:10.1093/europace/eux008)

16. BLANDINO A, TOSO E, SCAGLIONE M, ANSELMINO M, FERRARIS F, SARDI D, BATTAGLIA A, GAITA F. 2013 Long-Term Efficacy and Safety of Two Different Rhythm Control Strategies in Elderly Patients with Symptomatic Persistent Atrial Fibrillation. J. Cardiovasc. Electrophysiol. 24, 731-738. (doi:10.1111/jce.12126)

17. Mark DB et al. 2019 Effect of Catheter Ablation vs Medical Therapy on Quality of Life Among Patients With Atrial Fibrillation. JAMA 321, 1275. (doi:10.1001/jama.2019.0692)

18. Blomström-Lundqvist C et al. 2019 Effect of Catheter Ablation vs Antiarrhythmic Medication on Quality of Life in Patients With Atrial Fibrillation. JAMA 321, 1059. (doi:10.1001/jama.2019.0335)

19. Stabile G et al. 2014 Low incidence of permanent complications during catheter ablation for atrial fibrillation using open-irrigated catheters: a multicentre registry. EP Eur. 16, 1154-1159. (doi:10.1093/europace/euu002)

20. Gallo C et al. 2016 Long-term events following atrial fibrillation rate control or transcatheter ablation. J. Cardiovasc. Med. 17, 187-193. (doi:10.2459/JCM.0000000000000311)

21. Anselmino M, Rovera C, Marchetto G, Ferraris F, Castagno D, Gaita F. 2017 Anticoagulant cessation following atrial fibrillation ablation: limits of the ECG-guided 
approach. Expert Rev. Cardiovasc. Ther. 15, 473-479.

(doi:10.1080/14779072.2017.1332993)

22. Padeletti L et al. 2017 Pulmonary Vein Isolation with the Cryoballoon Technique:

Feasibility, Procedural Outcomes, and Adoption in the Real World: Data from One Shot Technologies TO Pulmonary Vein Isolation (1STOP) Project. PACE - Pacing Clin.

Electrophysiol. (doi:10.1111/pace.12975)

23. Kuck K-H et al. 2016 Cryoballoon or Radiofrequency Ablation for Paroxysmal Atrial Fibrillation. N. Engl. J. Med. 374, 2235-2245. (doi:10.1056/NEJMoa1602014)

24. Heidbuchel H et al. 2014 Practical ways to reduce radiation dose for patients and staff during device implantations and electrophysiological procedures. EP Eur. 16, 946-964. (doi:10.1093/europace/eut409)

25. Casella $\mathrm{M}$ et al. 2016 Near zerO fluoroscopic exPosure during catheter ablAtion of supRavenTricular arrhY thmias: the NO-PARTY multicentre randomized trial. Europace 18, 1565-1572. (doi:10.1093/europace/euv344) 
Figure 1: Patient flow for Italy.

\section{Fig. 1 - Patient Flow for ITALY}

318 patients included

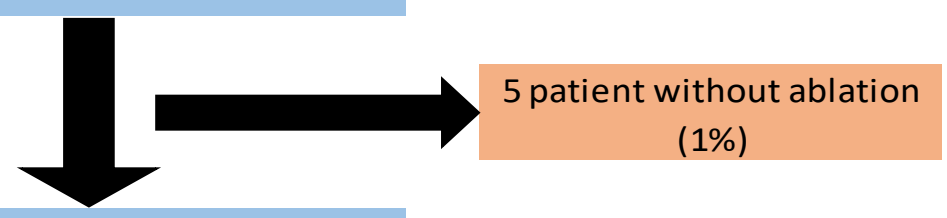

312 patients with ablation performed

1 patients with ablation partially done

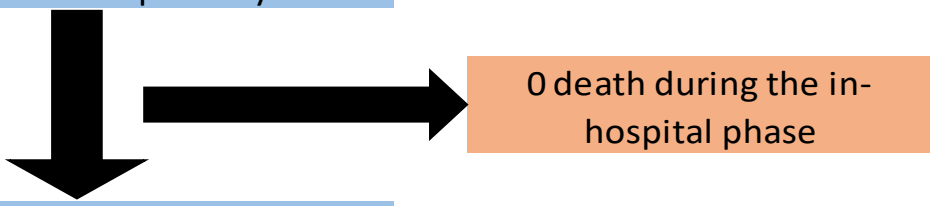

313 patients at discharge

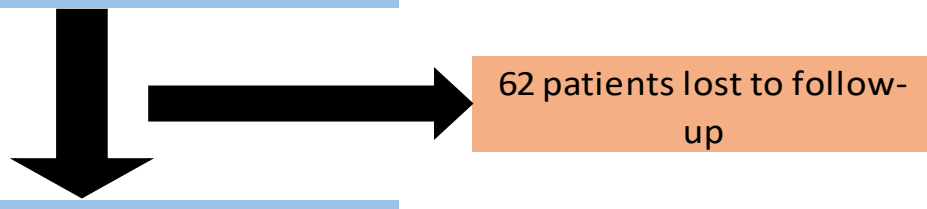

251 patients at 12 -month follow-up 
Figure 2: Kaplan-Meier curves for time to first arrhythmia recurrence in Italy versus the other enrolling countries.

Figure 5:Kaplan-Meier curves for time to first recurrence in ITALY versus rest of countries.

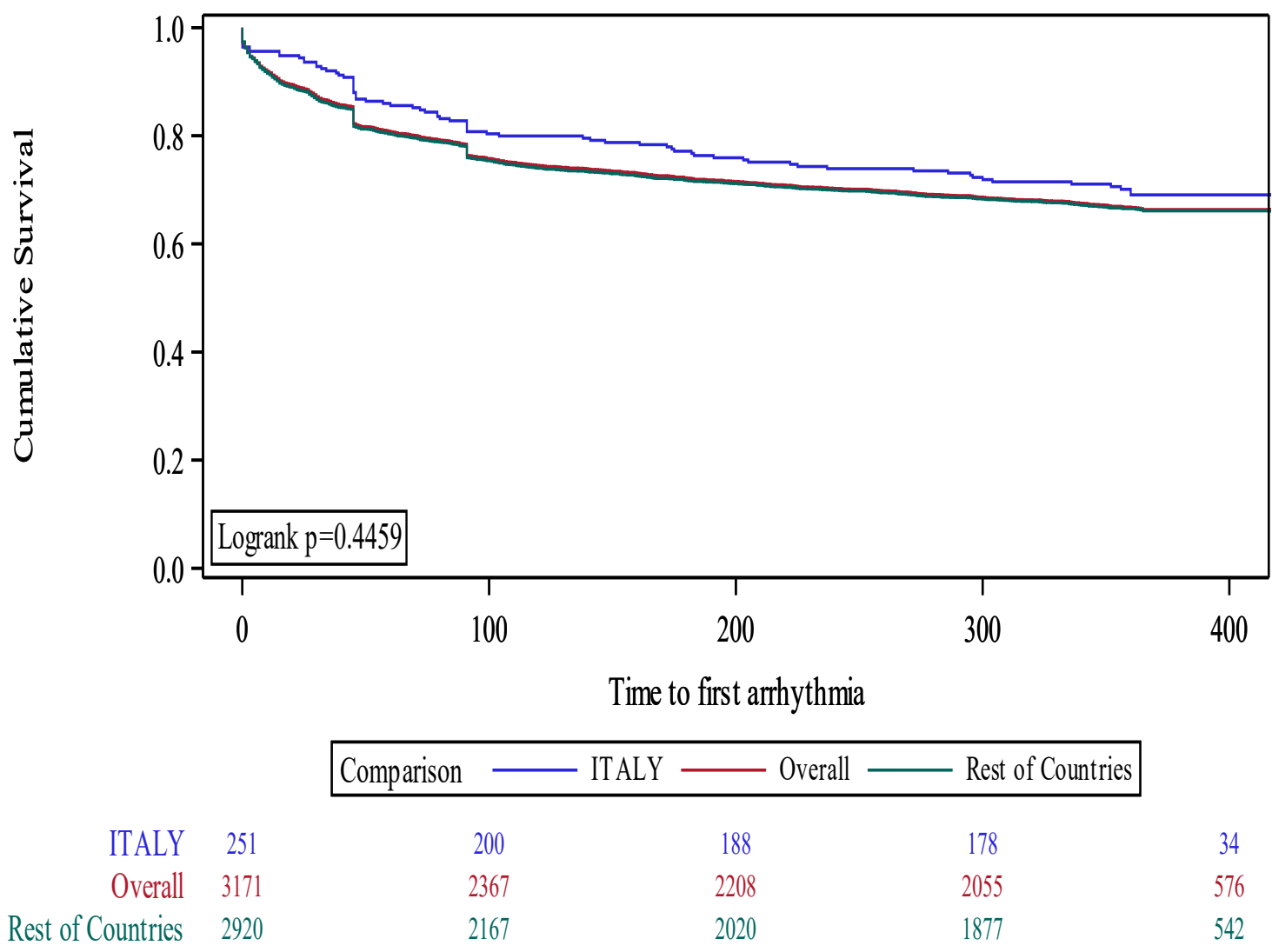


Figure 3: EHRA score for symptoms at inclusion and 1-year follow-up (a) and use of anticoagulants by CHA2DS2-VASc score (b) in Italy.
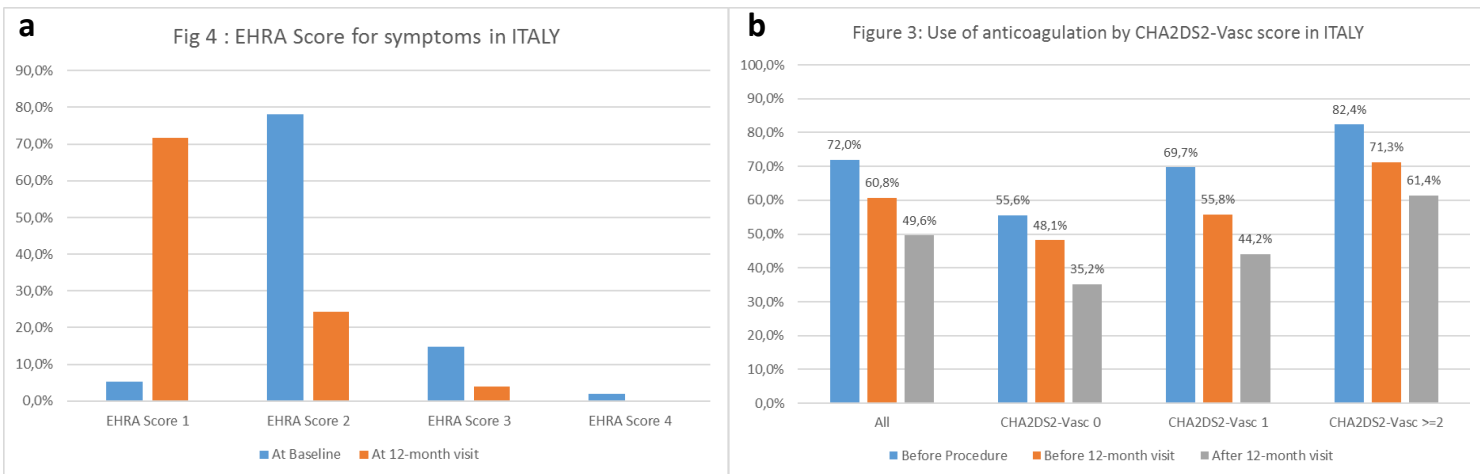

*P-values are from a Wilcoxon rank sign test. 
Table 1: Baseline clinical characteristics: Italy vs. other participating countries

\begin{tabular}{|c|c|c|c|c|}
\hline & Total & ITALY & Other countries & $P$ value \\
\hline \multicolumn{5}{|l|}{ Age (years) } \\
\hline $\mathrm{N}$ & 3592 & 313 & 3279 & \\
\hline Median (IQR) & $59.0[52.0-65.0]$ & $60.0[54.0-66.0]$ & $59.0[52.0-65.0]$ & $0.0510^{*}$ \\
\hline Females (\%) & $1146 / 3593(31.9 \%)$ & $74 / 313(23.6 \%)$ & $1072 / 3280(32.7 \%)$ & $0.0010^{* *}$ \\
\hline Caucasian (\%) & $3111 / 3429$ (90.7\%) & $308 / 313$ (98.4\%) & $2803 / 3116(90.0 \%)$ & $<0.0001^{* *}$ \\
\hline Body Mass Index >30 kg/m² (\%) & $1047 / 3333(31.4 \%)$ & $42 / 268(15.7 \%)$ & $1005 / 3065$ (32.8\%) & $<0.0001^{* *}$ \\
\hline \multicolumn{5}{|l|}{ Cardiovascular risk factors (\%) } \\
\hline Diabetes mellitus & $347 / 3583$ (9.7\%) & $31 / 313(9.9 \%)$ & $316 / 3270(9.7 \%)$ & $0.8907^{* *}$ \\
\hline Hypertension & $1954 / 3579$ (54.6\%) & $190 / 311(61.1 \%)$ & $1764 / 3268(54.0 \%)$ & $0.0160 * *$ \\
\hline Former smokers ( $>1$ year) & $653 / 3432(19.0 \%)$ & $40 / 297(13.5 \%)$ & $613 / 3135(19.6 \%)$ & $0.0107^{* *}$ \\
\hline Hypercholesterolemia & $1159 / 3517(33.0 \%)$ & $100 / 308(32.5 \%)$ & $1059 / 3209$ (33.0\%) & $0.8491^{* *}$ \\
\hline $\begin{array}{l}\text { Ischaemic thromboembolic events } \\
\text { (\%) }\end{array}$ & $230 / 3576(6.4 \%)$ & $20 / 313(6.4 \%)$ & $210 / 3263(6.4 \%)$ & $0.9747^{* *}$ \\
\hline \multicolumn{5}{|l|}{ Implanted devices } \\
\hline PM & $116 / 3590(3.2 \%)$ & $4 / 313(1.3 \%)$ & $112 / 3277(3.4 \%)$ & $0.0408 * *$ \\
\hline ICD & $27 / 3588(0.8 \%)$ & $3 / 313$ (1.0\%) & $24 / 3275(0.7 \%)$ & $0.5073 * * *$ \\
\hline CRT-P & $5 / 3588(0.1 \%)$ & 0 & $5 / 3275(0.2 \%)$ & NA \\
\hline CRT-D & $7 / 3588(0.2 \%)$ & $1 / 313(0.3 \%)$ & $6 / 3275(0.2 \%)$ & $0.4724 * * *$ \\
\hline
\end{tabular}




\begin{tabular}{|c|c|c|c|c|}
\hline & Total & ITALY & Other countries & $P$ value \\
\hline \multicolumn{5}{|c|}{ CHA2DS2-VASC } \\
\hline 0 & $805 / 3476(23.2 \%)$ & $68 / 295$ (23.1\%) & 737/3181 (23.2\%) & \multirow[t]{8}{*}{$0.5552^{*}$} \\
\hline 1 & $1038 / 3476$ (29.9\%) & $94 / 295$ (31.9\%) & $944 / 3181$ (29.7\%) & \\
\hline 2 & $810 / 3476(23.3 \%)$ & $66 / 295$ (22.4\%) & $744 / 3181(23.4 \%)$ & \\
\hline 3 & $525 / 3476(15.1 \%)$ & $48 / 295$ (16.3\%) & $477 / 3181$ (15.0\%) & \\
\hline 4 & $197 / 3476$ (5.7\%) & $13 / 295$ (4.4\%) & $184 / 3181(5.8 \%)$ & \\
\hline 5 & $70 / 3476$ (2.0\%) & $5 / 295$ (1.7\%) & $65 / 3181(2.0 \%)$ & \\
\hline 6 & $24 / 3476(0.7 \%)$ & 0 & $24 / 3181(0.8 \%)$ & \\
\hline 7 & $7 / 3476(0.2 \%)$ & $1 / 295(0.3 \%)$ & $6 / 3181(0.2 \%)$ & \\
\hline \multicolumn{5}{|c|}{ HAS-BLED } \\
\hline 0 & $2063 / 3357$ (61.5\%) & $186 / 284(65.5 \%)$ & $1877 / 3073$ (61.1\%) & \multirow[t]{5}{*}{$0.1201 *$} \\
\hline 1 & $1009 / 3357$ (30.1\%) & $79 / 284(27.8 \%)$ & $930 / 3073(30.3 \%)$ & \\
\hline 2 & 241/3357 (7.2\%) & $16 / 284(5.6 \%)$ & $225 / 3073(7.3 \%)$ & \\
\hline 3 & $39 / 3357$ (1.2\%) & $2 / 284(0.7 \%)$ & $37 / 3073(1.2 \%)$ & \\
\hline 4 & $5 / 3357(0.1 \%)$ & $1 / 284(0.4 \%)$ & 4/3073 (0.1\%) & \\
\hline$<3$ & $3313 / 3357$ (98.7\%) & $281 / 284$ (98.9\%) & $3032 / 3073$ (98.7\%) & \multirow[t]{2}{*}{$1.0000 * * *$} \\
\hline$>=3$ & $44 / 3357$ (1.3\%) & $3 / 284$ (1.1\%) & $41 / 3073(1.3 \%)$ & \\
\hline $\begin{array}{l}\text { Numbe } \\
\text { month }\end{array}$ & & & & \\
\hline
\end{tabular}




\begin{tabular}{|c|c|c|c|c|}
\hline & Total & ITALY & Other countries & $P$ value \\
\hline $\mathrm{N}$ & 1978 & 189 & 1789 & \\
\hline Median (IQR) & $3.0[1.0-7.0]$ & $2.0[1.0-4.0]$ & $3.0[1.0-8.0]$ & $<0.0001^{*}$ \\
\hline \multicolumn{5}{|l|}{ AFib Underlying disorder (\%) } \\
\hline Lone atrial fibrillation & $1165 / 3593(32.4 \%)$ & $97 / 313(31.0 \%)$ & $1068 / 3280(32.6 \%)$ & $0.5706 * *$ \\
\hline $\begin{array}{l}\text { Hypertension without known } \\
\text { hypertensive cardiomyopathy }\end{array}$ & $1336 / 3579$ (37.3\%) & $49 / 311$ (15.8\%) & $1287 / 3268(39.4 \%)$ & $<0.0001^{* *}$ \\
\hline Hypertensive cardiomyopathy & $623 / 2423(25.7 \%)$ & $143 / 216(66.2 \%)$ & $480 / 2207$ (21.7\%) & $<0.0001^{* *}$ \\
\hline Coronary artery disease & $449 / 2380$ (18.9\%) & $25 / 211(11.8 \%)$ & $424 / 2169$ (19.5\%) & $0.0063^{* *}$ \\
\hline Dilated cardiomyopathy & $74 / 2426(3.1 \%)$ & $7 / 215(3.3 \%)$ & $67 / 2211(3.0 \%)$ & $0.8544^{* *}$ \\
\hline Hypertrophic cardiomyopathy & $55 / 2426(2.3 \%)$ & $5 / 215(2.3 \%)$ & $50 / 2211(2.3 \%)$ & $0.8134^{* * *}$ \\
\hline Chronic Heart Failure & $537 / 2418(22.2 \%)$ & $19 / 214(8.9 \%)$ & $518 / 2204(23.5 \%)$ & $<0.0001^{* *}$ \\
\hline Other cardiac disease & $158 / 2415$ (6.5\%) & $9 / 215$ (4.2\%) & $149 / 2200(6.8 \%)$ & $0.1432^{* *}$ \\
\hline Hyperthyroidism & $84 / 3519(2.4 \%)$ & $11 / 313(3.5 \%)$ & $73 / 3206(2.3 \%)$ & $0.1710^{* *}$ \\
\hline \multicolumn{5}{|l|}{ AFib Precipating factors (\%) } \\
\hline Physical exercice & $389 / 3502$ (11.1\%) & $7 / 313(2.2 \%)$ & $382 / 3189$ (12.0\%) & $<0.0001^{* *}$ \\
\hline Alcohol abuse & $146 / 3481(4.2 \%)$ & $1 / 313(0.3 \%)$ & $145 / 3168(4.6 \%)$ & $0.0003^{* *}$ \\
\hline Heart failure & $180 / 3559$ (5.1\%) & 0 & $180 / 3246(5.5 \%)$ & NA \\
\hline Thyreotoxicosis & $57 / 3555(1.6 \%)$ & $4 / 313(1.3 \%)$ & $53 / 3242(1.6 \%)$ & $0.6312^{* *}$ \\
\hline Sexual activity & $81 / 3407$ (2.4\%) & 0 & $81 / 3094(2.6 \%)$ & NA \\
\hline
\end{tabular}




\begin{tabular}{|c|c|c|c|c|}
\hline & Total & ITALY & Other countries & $P$ value \\
\hline Surgical intervention & $39 / 3560(1.1 \%)$ & $4 / 313(1.3 \%)$ & $35 / 3247(1.1 \%)$ & $0.7728 * * *$ \\
\hline Pulmonary infection & $25 / 3561(0.7 \%)$ & $2 / 313(0.6 \%)$ & $23 / 3248(0.7 \%)$ & $1.0000^{* * *}$ \\
\hline Acute pericarditis & $3 / 3564(0.1 \%)$ & 0 & $3 / 3251(0.1 \%)$ & NA \\
\hline Postprandial & $158 / 3489(4.5 \%)$ & $10 / 313(3.2 \%)$ & $148 / 3176(4.7 \%)$ & $0.2343^{* *}$ \\
\hline Prior history of atrial flutter (\%) & $840 / 3461(24.3 \%)$ & $87 / 309$ (28.2\%) & $753 / 3152$ (23.9\%) & $0.0951 * *$ \\
\hline $\begin{array}{l}\text { Cavotricuspid-dependent flutter } \\
\text { (\%) }\end{array}$ & $565 / 667(84.7 \%)$ & $61 / 77(79.2 \%)$ & $504 / 590(85.4 \%)$ & $0.1549 * *$ \\
\hline EHRA score for symptoms (\%) & & & & \\
\hline 1 & $107 / 3589$ (3.0\%) & $24 / 312(7.7 \%)$ & $83 / 3277(2.5 \%)$ & $<0.0001^{*}$ \\
\hline 2 & $1941 / 3589$ (54.1\%) & $240 / 312(76.9 \%)$ & $1701 / 3277$ (51.9\%) & \\
\hline 3 & $1391 / 3589(38.8 \%)$ & $43 / 312(13.8 \%)$ & $1348 / 3277(41.1 \%)$ & \\
\hline 4 & $150 / 3589(4.2 \%)$ & $5 / 312(1.6 \%)$ & $145 / 3277(4.4 \%)$ & \\
\hline $\begin{array}{l}\text { Associated symptoms (EHRA score } \\
>1 \text { ) }\end{array}$ & $3482 / 3589$ (97.0\%) & $288 / 312(92.3 \%)$ & $3194 / 3277$ (97.5\%) & $<0.0001^{* *}$ \\
\hline Palpitations & $2966 / 3482(85.2 \%)$ & $253 / 288(87.8 \%)$ & $2713 / 3194(84.9 \%)$ & $0.1836^{* *}$ \\
\hline Fatigue & $1725 / 3482(49.5 \%)$ & $106 / 288(36.8 \%)$ & $1619 / 3194(50.7 \%)$ & $<0.0001^{* *}$ \\
\hline Dyspnoea & $1424 / 3482$ (40.9\%) & $93 / 288(32.3 \%)$ & $1331 / 3194(41.7 \%)$ & $0.0019 * *$ \\
\hline Weakness & $1415 / 3482(40.6 \%)$ & $43 / 288$ (14.9\%) & $1372 / 3194(43.0 \%)$ & $<0.0001^{* *}$ \\
\hline Diziness/presyncope & $621 / 3482(17.8 \%)$ & $11 / 288(3.8 \%)$ & 610/3194 (19.1\%) & $<0.0001^{* *}$ \\
\hline
\end{tabular}




\begin{tabular}{|c|c|c|c|c|}
\hline & Total & ITALY & Other countries & $P$ value \\
\hline Chest pain & $560 / 3482(16.1 \%)$ & $11 / 288(3.8 \%)$ & $549 / 3194(17.2 \%)$ & $<0.0001^{* *}$ \\
\hline Syncope & $143 / 3482$ (4.1\%) & $13 / 288(4.5 \%)$ & $130 / 3194(4.1 \%)$ & $0.7163^{* *}$ \\
\hline Prior cardioversions (\%) & $2292 / 3457$ (66.3\%) & $223 / 308(72.4 \%)$ & $2069 / 3149$ (65.7\%) & $0.0176^{* *}$ \\
\hline Electrical & $1476 / 3512(42.0 \%)$ & $154 / 308(50.0 \%)$ & $1322 / 3204(41.3 \%)$ & $0.0030 * *$ \\
\hline Pharmacological & $1365 / 3400(40.1 \%)$ & $131 / 306(42.8 \%)$ & 1234/3094 (39.9\%) & $0.3191 * *$ \\
\hline $\begin{array}{l}\text { Previous antiarrhythmic drug trial } \\
\text { (\%) }\end{array}$ & $3202 / 3558$ (90.0\%) & 291/311 (93.6\%) & 2911/3247 (89.7\%) & $0.0279 * *$ \\
\hline Flecainide & $1084 / 3178$ (34.1\%) & $169 / 290(58.3 \%)$ & $915 / 2888$ (31.7\%) & $<0.0001^{* *}$ \\
\hline Propafenone & $1120 / 3179$ (35.2\%) & $82 / 288(28.5 \%)$ & $1038 / 2891$ (35.9\%) & $0.0118^{* *}$ \\
\hline Amiodarone & $1686 / 3184(53.0 \%)$ & $131 / 289(45.3 \%)$ & $1555 / 2895$ (53.7\%) & $0.0065^{* *}$ \\
\hline Sotalol & $923 / 3176(29.1 \%)$ & $62 / 288(21.5 \%)$ & $861 / 2888$ (29.8\%) & $0.0031^{* *}$ \\
\hline Quinidine & $34 / 3172(1.1 \%)$ & $5 / 288(1.7 \%)$ & $29 / 2884(1.0 \%)$ & $0.2294 * * *$ \\
\hline Dronedarone & $256 / 3173(8.1 \%)$ & $10 / 288(3.5 \%)$ & $246 / 2885$ (8.5\%) & $0.0027^{* *}$ \\
\hline Disopyramide & $28 / 3172(0.9 \%)$ & $6 / 288(2.1 \%)$ & $22 / 2884(0.8 \%)$ & $0.0362 * * *$ \\
\hline Other & $343 / 3172(10.8 \%)$ & $16 / 288(5.6 \%)$ & $327 / 2884(11.3 \%)$ & $0.0026 * *$ \\
\hline \multicolumn{5}{|l|}{ Number of previous drug trials } \\
\hline $\mathrm{N}$ & 3202 & 291 & 2911 & \\
\hline Median (IQR) & $1.0[1.0-2.0]$ & $1.0[1.0-2.0]$ & $1.0[1.0-2.0]$ & $0.5426^{*}$ \\
\hline Reasons for AFib ablation & & & & \\
\hline
\end{tabular}




\begin{tabular}{|c|c|c|c|c|}
\hline & Total & ITALY & Other countries & $P$ value \\
\hline Symptoms & $3272 / 3593$ (91.1\%) & $275 / 313$ (87.9\%) & $2997 / 3280(91.4 \%)$ & $0.0374 * *$ \\
\hline Quality of life & $2377 / 3593(66.2 \%)$ & $175 / 313(55.9 \%)$ & $2202 / 3280(67.1 \%)$ & $<0.0001^{* *}$ \\
\hline Desire for drug-free lifestyle & $1068 / 3593(29.7 \%)$ & $77 / 313(24.6 \%)$ & $991 / 3280(30.2 \%)$ & $0.0379 * *$ \\
\hline Desire for sinus rhythm & $1280 / 3593(35.6 \%)$ & $130 / 313(41.5 \%)$ & $1150 / 3280(35.1 \%)$ & $0.0223 * *$ \\
\hline $\begin{array}{l}\text { Indications according to the } \\
\text { recommendations of the } 2010 \text { ESC } \\
\text { AFib guidelines }\end{array}$ & & & & \\
\hline $\begin{array}{l}\text { Paroxysmal AF previously failed } \\
\text { antiarrhythmic medication (Class } \\
\text { Ila) }\end{array}$ & $2146 / 3593(59.7 \%)$ & $170 / 313(54.3 \%)$ & $1976 / 3280(60.2 \%)$ & $0.0409 * *$ \\
\hline $\begin{array}{l}\text { Persistent symptomatic AF } \\
\text { refractory to antiarrhythmic } \\
\text { therapy (Class Ila) }\end{array}$ & $925 / 3593(25.7 \%)$ & $93 / 313(29.7 \%)$ & $832 / 3280(25.4 \%)$ & $0.0929 * *$ \\
\hline $\begin{array}{l}\text { Heart failure with antiarrhythmic } \\
\text { medication, including amiodarone, } \\
\text { fails to control symptoms (Class IIb) }\end{array}$ & $53 / 3593(1.5 \%)$ & $13 / 313(4.2 \%)$ & $40 / 3280(1.2 \%)$ & $0.0004^{* * *}$ \\
\hline $\begin{array}{l}\text { Prior to antiarrhythmic drug } \\
\text { therapy in symptomatic patients } \\
\text { despite adequate rate control with } \\
\text { paroxysmal AF and no significant } \\
\text { underlying heart disease (Class IIb) }\end{array}$ & $157 / 3593(4.4 \%)$ & $6 / 313(1.9 \%)$ & $151 / 3280(4.6 \%)$ & $0.0263 * *$ \\
\hline
\end{tabular}




\begin{tabular}{|l|c|c|c|c|}
\hline & Total & ITALY & Other countries & P value \\
\hline Symptomatic long-standing & $147 / 3593(4.1 \%)$ & $5 / 313(1.6 \%)$ & $142 / 3280(4.3 \%)$ & $0.0197^{* *}$ \\
persistent AF refractory to & & & & \\
antiarrhythmic drugs (Class IIb) & & & & $139 / 3280(4.2 \%)$ \\
\hline Other & $165 / 3593(4.6 \%)$ & $26 / 313(8.3 \%)$ & $0.0010^{* *}$ \\
\hline
\end{tabular}

IQR, interquartile range; SBP, Systolic Blood Pressure; PM, pacemaker; ICD, implantable cardioverter defibrillator. CRT, cardiac resynchronization therapy. Unknown or missing values are not taken into account.

*P-values for among-group comparisons are from Kruskal-Wallis test.

**P-values for among-group comparisons are from Pearson's test.

***P-values for among-group comparisons are from Fisher's exact test. 
Table 2: Technical characteristics of the procedure and ablation strategy by type of atrial fibrillation: Italy vs other participating countries

\begin{tabular}{|c|c|c|c|c|}
\hline & Total & ITALY & Other countries & $P$ value \\
\hline Type of procedure (\%) & & & & \\
\hline First procedure & $2815 / 3592(78.4 \%)$ & $245 / 313(78.3 \%)$ & $2570 / 3279$ (78.4\%) & $0.9663^{* *}$ \\
\hline Redo due to Atrial Fibrillation & 685/3592 (19.1\%) & $57 / 313(18.2 \%)$ & $628 / 3279(19.2 \%)$ & $0.6855^{* *}$ \\
\hline $\begin{array}{l}\text { Redo due to Left Atrial Flutter/Left } \\
\text { Atrial Tachycardia }\end{array}$ & $92 / 3592(2.6 \%)$ & $11 / 313(3.5 \%)$ & $81 / 3279(2.5 \%)$ & $0.2639 * *$ \\
\hline Hybrid AF ablation (\%) & $11 / 3592(0.3 \%)$ & 0 & $11 / 3279(0.3 \%)$ & NA \\
\hline Use of 3D mapping system (\%) & $2864 / 3592(79.7 \%)$ & $242 / 313(77.3 \%)$ & $2622 / 3279(80.0 \%)$ & $0.2657^{* *}$ \\
\hline $\begin{array}{l}\text { Use of remote navigation and } \\
\text { ablation system (\%) }\end{array}$ & 190/3592 (5.3\%) & $10 / 313(3.2 \%)$ & $180 / 3279(5.5 \%)$ & $0.0831^{* *}$ \\
\hline $\begin{array}{l}\text { Use of rotational angiography for } \\
\text { 3D reconstruction (\%) }\end{array}$ & $142 / 3592(4.0 \%)$ & $43 / 313(13.7 \%)$ & $99 / 3279(3.0 \%)$ & $<0.0001^{* *}$ \\
\hline $\begin{array}{l}\text { Use of circular mapping catheter } \\
\text { (\%) }\end{array}$ & $2937 / 3592(81.8 \%)$ & $224 / 313(71.6 \%)$ & $2713 / 3279(82.7 \%)$ & $<0.0001 * *$ \\
\hline Use of image fusion (\%) & $1272 / 3591(35.4 \%)$ & $160 / 313(51.1 \%)$ & $1112 / 3278(33.9 \%)$ & $<0.0001^{* *}$ \\
\hline CT & $986 / 1272(77.5 \%)$ & $64 / 160(40.0 \%)$ & $922 / 1112$ (82.9\%) & $<0.0001^{* *}$ \\
\hline MRI & $180 / 1272(14.2 \%)$ & $54 / 160(33.8 \%)$ & $126 / 1112(11.3 \%)$ & $<0.0001^{* *}$ \\
\hline Rotational Angiography & $96 / 1272(7.5 \%)$ & $41 / 160(25.6 \%)$ & $55 / 1112(4.9 \%)$ & $<0.0001 * *$ \\
\hline
\end{tabular}




\begin{tabular}{|c|c|c|c|c|}
\hline & Total & ITALY & Other countries & $P$ value \\
\hline Other & $10 / 1272(0.8 \%)$ & $1 / 160(0.6 \%)$ & $9 / 1112(0.8 \%)$ & $1.0000 * * *$ \\
\hline $\begin{array}{l}\text { General anaesthesia during } \\
\text { procedure (\%) }\end{array}$ & $809 / 3592(22.5 \%)$ & $9 / 313(2.9 \%)$ & $800 / 3279(24.4 \%)$ & $<0.0001^{* *}$ \\
\hline \multicolumn{5}{|l|}{ Energy source (\%) } \\
\hline Non-irrigated radiofrequency & $51 / 3591(1.4 \%)$ & 0 & $51 / 3278(1.6 \%)$ & NA \\
\hline $\begin{array}{l}\text { Radiofrequency with closed } \\
\text { irrigation }\end{array}$ & $126 / 3591(3.5 \%)$ & $6 / 313(1.9 \%)$ & $120 / 3278(3.7 \%)$ & $0.1092 * *$ \\
\hline $\begin{array}{l}\text { Radiofrequency with open } \\
\text { irrigation }\end{array}$ & $2751 / 3591(76.6 \%)$ & $290 / 313(92.7 \%)$ & $2461 / 3278(75.1 \%)$ & $<0.0001^{* *}$ \\
\hline Cryo & $571 / 3591(15.9 \%)$ & $13 / 313(4.2 \%)$ & $558 / 3278(17.0 \%)$ & $<0.0001^{* *}$ \\
\hline $\begin{array}{l}\text { Duty-cycled radiofrequency } \\
\text { energy }\end{array}$ & $61 / 3591(1.7 \%)$ & $5 / 313(1.6 \%)$ & $56 / 3278(1.7 \%)$ & $0.8846 * *$ \\
\hline $\begin{array}{l}\text { Laser balloon (endoscopic } \\
\text { ablation system) }\end{array}$ & $25 / 3591(0.7 \%)$ & 0 & $25 / 3278(0.8 \%)$ & NA \\
\hline High intensity focused ultrasound & $8 / 3591(0.2 \%)$ & 0 & $8 / 3278(0.2 \%)$ & NA \\
\hline \multicolumn{5}{|l|}{ Procedure duration (min) } \\
\hline $\mathrm{N}$ & 3339 & 289 & 3050 & \\
\hline Median (IQR) & $160.0[120.0-200.0]$ & $145.0[110.0-180.0]$ & $160.0[120.0-200.0]$ & $0.0005^{*}$ \\
\hline \multicolumn{5}{|l|}{ Fluoroscopy total time (min) } \\
\hline $\mathrm{N}$ & 3344 & 284 & 3060 & \\
\hline
\end{tabular}




\begin{tabular}{|c|c|c|c|c|}
\hline & Total & ITALY & Other countries & $P$ value \\
\hline Median (IQR) & $19.7[10.7-33.1]$ & $16.9[8.4-29.7]$ & $20.0[11.0-33.8]$ & $0.0018^{*}$ \\
\hline Radiation dose (mGy) & & & & \\
\hline $\mathrm{N}$ & 891 & 53 & 838 & \\
\hline Median (IQR) & $386.0[167.0-852.0]$ & $477.0[170.0-758.0]$ & $379.0[167.0-889.0]$ & $0.9038^{*}$ \\
\hline Radiation dose $\left(\mathrm{Gy} / \mathrm{cm}^{2}\right)$ & & & & \\
\hline $\mathrm{N}$ & 1872 & 158 & 1714 & \\
\hline Median (IQR) & $27.3[10.0-59.5]$ & $37.5[19.0-65.5]$ & $26.0[9.5-59.3]$ & $0.0022 *$ \\
\hline $\begin{array}{l}\text { Transesophageal echocardiogram } \\
\text { (\%) }\end{array}$ & $550 / 2783(19.8 \%)$ & 0 & $550 / 2542(21.6 \%)$ & NA \\
\hline Intracardiac echocardiogram (\%) & $457 / 3592(12.7 \%)$ & $7 / 313(2.2 \%)$ & $450 / 3279(13.7 \%)$ & $<0.0001^{* *}$ \\
\hline $\begin{array}{l}\text { Esophageal monitoring during } \\
\text { procedure (\%) }\end{array}$ & $319 / 3592(8.9 \%)$ & $34 / 313(10.9 \%)$ & $285 / 3279(8.7 \%)$ & $0.1970 * *$ \\
\hline Temperature probe & $277 / 319(86.8 \%)$ & $31 / 34(91.2 \%)$ & $246 / 285(86.3 \%)$ & $0.5940 * * *$ \\
\hline Electroanatomical mapping & $5 / 319(1.6 \%)$ & $3 / 34(8.8 \%)$ & $2 / 285(0.7 \%)$ & $0.0096 * * *$ \\
\hline Transeophageal echo & $36 / 319(11.3 \%)$ & 0 & $36 / 285(12.6 \%)$ & NA \\
\hline Other & $1 / 319(0.3 \%)$ & 0 & $1 / 285(0.4 \%)$ & NA \\
\hline Attempt of PV isolation (overall) (\%) & $3509 / 3548$ (98.9\%) & $306 / 308$ (99.4\%) & $3203 / 3240$ (98.9\%) & $0.5758^{* * *}$ \\
\hline $\begin{array}{l}\text { Achievement of PV entrance block } \\
\text { (\%) }\end{array}$ & & & & \\
\hline
\end{tabular}




\begin{tabular}{|c|c|c|c|c|}
\hline & Total & ITALY & Other countries & $P$ value \\
\hline LSPV & $3261 / 3374(96.7 \%)$ & 297/301 (98.7\%) & $2964 / 3073$ (96.5\%) & $0.0412^{* *}$ \\
\hline LIPV & $3193 / 3293(97.0 \%)$ & $288 / 290(99.3 \%)$ & 2905/3003 (96.7\%) & $0.0147^{* *}$ \\
\hline RSPV & $3236 / 3359$ (96.3\%) & $281 / 288(97.6 \%)$ & 2955/3071 (96.2\%) & $0.2446 * *$ \\
\hline RIPV & $3206 / 3352$ (95.6\%) & $287 / 291(98.6 \%)$ & 2919/3061 (95.4\%) & $0.0091^{* *}$ \\
\hline Atrial linear lesion (overall) (\%) & $1156 / 3540(32.7 \%)$ & $102 / 312(32.7 \%)$ & $1054 / 3228(32.7 \%)$ & $0.9884 * *$ \\
\hline Left atrial linear lesion (\%) & $606 / 3527(17.2 \%)$ & $52 / 312(16.7 \%)$ & $554 / 3215(17.2 \%)$ & $0.8006^{* *}$ \\
\hline Roof line & $511 / 3591(14.2 \%)$ & $45 / 312(14.4 \%)$ & $466 / 3279(14.2 \%)$ & $0.9186^{* *}$ \\
\hline Mitral isthmus line & 262/3591 (7.3\%) & $32 / 312(10.3 \%)$ & $230 / 3279(7.0 \%)$ & $0.0354^{* *}$ \\
\hline Posterior line & $160 / 3515(4.6 \%)$ & $36 / 312(11.5 \%)$ & $124 / 3203$ (3.9\%) & $<0.0001^{* *}$ \\
\hline Other left atrial linear lesion & $122 / 3591$ (3.4\%) & $14 / 312(4.5 \%)$ & $108 / 3279(3.3 \%)$ & $0.2662^{* *}$ \\
\hline Right atrial linear lesion (\%) & $716 / 3530(20.3 \%)$ & $66 / 312(21.2 \%)$ & $650 / 3218(20.2 \%)$ & $0.6888 * *$ \\
\hline Superior vena cava & $57 / 3591(1.6 \%)$ & $2 / 312(0.6 \%)$ & $55 / 3279(1.7 \%)$ & $0.2324 * * *$ \\
\hline Cavotricuspid isthmus ablation & $660 / 3591(18.4 \%)$ & $55 / 312(17.6 \%)$ & $605 / 3279(18.5 \%)$ & $0.7200 * *$ \\
\hline Other right atrial linear lesion & $29 / 3515(0.8 \%)$ & $10 / 312(3.2 \%)$ & $19 / 3203(0.6 \%)$ & $0.0001 * * *$ \\
\hline $\begin{array}{l}\text { Ablation at fractionated } \\
\text { electrogram sites (\%) }\end{array}$ & $349 / 3590(9.7 \%)$ & $63 / 311(20.3 \%)$ & $286 / 3279(8.7 \%)$ & $<0.0001^{* *}$ \\
\hline $\begin{array}{l}\text { Ablation of autonomic ganglionated } \\
\text { plexi }\end{array}$ & $326 / 3590(9.1 \%)$ & $36 / 311(11.6 \%)$ & $290 / 3279(8.8 \%)$ & $0.1091^{* *}$ \\
\hline
\end{tabular}




\begin{tabular}{|l|c|c|c|c|}
\hline & Total & ITALY & Other countries & P value \\
\hline Use of adenosine at end of & $367 / 3591(10.2 \%)$ & $37 / 312(11.9 \%)$ & $330 / 3279(10.1 \%)$ & $0.3172^{* *}$ \\
procedure (\%) & & & & \\
\hline
\end{tabular}

Unknown or missing values are not taken into account.

*P-values for among-group comparisons are from Kruskal-Wallis test.

**P-values for among-group comparisons are from Pearson's test.

***P-values for among-group comparisons are from Fisher's exact test. 
Table 3: Adverse events associated with catheter ablation of atrial fibrillation: Italy vs other participating countries

\begin{tabular}{|c|c|c|c|c|}
\hline & Total & ITALY & $\begin{array}{l}\text { Other countries } \\
\qquad(n=3280)\end{array}$ & $P$ value \\
\hline Cardiovascular (\%) & $176 / 3592$ (4.9\%) & $3 / 313(1.0 \%)$ & $173 / 3279(5.3 \%)$ & $0.0007^{* *}$ \\
\hline Pericarditis & 30/3591 (0.8\%) & $2 / 313(0.6 \%)$ & $28 / 3278$ (0.9\%) & $1.0000 * * *$ \\
\hline Cardiac perforation & $52 / 3591(1.4 \%)$ & 0 & $52 / 3278(1.6 \%)$ & NA \\
\hline Acute myocardial Infarction & $2 / 3591(0.1 \%)$ & 0 & $2 / 3278(0.1 \%)$ & NA \\
\hline Endocarditis & $2 / 3591(0.1 \%)$ & 0 & $2 / 3278(0.1 \%)$ & NA \\
\hline Atypical atrial flutter (no AFib) & $11 / 3592(0.3 \%)$ & 0 & $11 / 3279(0.3 \%)$ & NA \\
\hline Bradycardia Requiring Pacemaker & 10/3591 (0.3\%) & $1 / 313(0.3 \%)$ & $9 / 3278(0.3 \%)$ & $0.5988 * * *$ \\
\hline Cardiac Arrest & $3 / 3591(0.1 \%)$ & 0 & $3 / 3278(0.1 \%)$ & NA \\
\hline Air embolism & $9 / 3591(0.3 \%)$ & 0 & $9 / 3278(0.3 \%)$ & NA \\
\hline Cardiac thromboembolic event & $2 / 3591(0.1 \%)$ & 0 & $2 / 3278(0.1 \%)$ & NA \\
\hline Heart valve damage & 3/3591 (0.1\%) & 0 & $3 / 3278(0.1 \%)$ & NA \\
\hline Other & 69/3591 (1.9\%) & 0 & $69 / 3278$ (2.1\%) & NA \\
\hline Peripheral/Vascular (\%) & $64 / 3592(1.8 \%)$ & $3 / 313(1.0 \%)$ & $61 / 3279$ (1.9\%) & $0.2492 * *$ \\
\hline AV fistula & $22 / 3592(0.6 \%)$ & $1 / 313(0.3 \%)$ & $21 / 3279(0.6 \%)$ & $0.7159 * * *$ \\
\hline Pseudoaneurysm & $24 / 3592(0.7 \%)$ & $1 / 313(0.3 \%)$ & $23 / 3279(0.7 \%)$ & $0.7171 * * *$ \\
\hline $\begin{array}{l}\text { Hematoma or bleeding requiring } \\
\text { evacuation or transfusion }\end{array}$ & $14 / 3592(0.4 \%)$ & $1 / 313(0.3 \%)$ & $13 / 3279(0.4 \%)$ & $1.0000 * * *$ \\
\hline
\end{tabular}




\begin{tabular}{|c|c|c|c|c|}
\hline & Total & ITALY & $\begin{array}{l}\text { Other countries } \\
\qquad(n=3280)\end{array}$ & P value \\
\hline Peripheral thromboembolic event & $1 / 3592(0.0 \%)$ & 0 & $1 / 3279(0.0 \%)$ & NA \\
\hline Deep vein thrombosis & $2 / 3592(0.1 \%)$ & 0 & $2 / 3279(0.1 \%)$ & NA \\
\hline Neurological (\%) & $35 / 3592(1.0 \%)$ & 0 & $35 / 3279(1.1 \%)$ & NA \\
\hline Stroke & $5 / 3592(0.1 \%)$ & 0 & $5 / 3279(0.2 \%)$ & NA \\
\hline TIA & $14 / 3592(0.4 \%)$ & 0 & $14 / 3279(0.4 \%)$ & NA \\
\hline Phrenic Nerve Damage & $16 / 3592(0.4 \%)$ & 0 & $16 / 3279(0.5 \%)$ & NA \\
\hline Pulmonary (\%) & $21 / 3592(0.6 \%)$ & $4 / 313(1.3 \%)$ & $17 / 3279(0.5 \%)$ & $0.1040 * * *$ \\
\hline Hemothorax & $1 / 3592(0.0 \%)$ & 0 & $1 / 3279(0.0 \%)$ & NA \\
\hline Pleural Effusion & $5 / 3592(0.1 \%)$ & 0 & $5 / 3279(0.2 \%)$ & NA \\
\hline Pneumothorax & $5 / 3592(0.1 \%)$ & $1 / 313(0.3 \%)$ & 4/3279 (0.1\%) & $0.3663 * * *$ \\
\hline Pulmonary vein stenosis & $7 / 3592(0.2 \%)$ & $3 / 313(1.0 \%)$ & $4 / 3279(0.1 \%)$ & $0.0176 * * *$ \\
\hline Pneumonia & $3 / 3592(0.1 \%)$ & 0 & $3 / 3279(0.1 \%)$ & NA \\
\hline Gastrointestinal (\%) & $7 / 3592(0.2 \%)$ & 0 & $7 / 3279(0.2 \%)$ & NA \\
\hline Oesophageal ulceration & $3 / 3592(0.1 \%)$ & 0 & $3 / 3279(0.1 \%)$ & NA \\
\hline Esophageal fistula or perforation & $1 / 3592(0.0 \%)$ & 0 & $1 / 3279(0.0 \%)$ & NA \\
\hline $\begin{array}{l}\text { Gastric motility/pyloric spam } \\
\text { disorders }\end{array}$ & $3 / 3592(0.1 \%)$ & 0 & $3 / 3279(0.1 \%)$ & NA \\
\hline General (\%) & $14 / 3592(0.4 \%)$ & $2 / 313(0.6 \%)$ & $12 / 3279(0.4 \%)$ & $0.3481 * * *$ \\
\hline
\end{tabular}




\begin{tabular}{|l|c|c|c|c|}
\hline & & & Other countries & P value \\
& Total & ITALY & (n280) & 0.2479*** \\
\hline Allergic Reaction & $11 / 3592(0.3 \%)$ & $2 / 313(0.6 \%)$ & $9 / 3279(0.3 \%)$ & NA \\
\hline Sepsis & $1 / 3592(0.0 \%)$ & 0 & $1 / 3279(0.0 \%)$ & $0.0102^{* *}$ \\
\hline Other (\%) & $108 / 3591(3.0 \%)$ & $2 / 313(0.6 \%)$ & $106 / 3278(3.2 \%)$ & $1.0000^{* * *}$ \\
\hline Death (\%) & $15 / 3593(0.4 \%)$ & $1 / 313(0.3 \%)$ & $14 / 3280(0.4 \%)$ & NA \\
\hline Cardiac & $4 / 15(26.7 \%)$ & 0 & $4 / 14(28.6 \%)$ & NA \\
\hline Vascular & $4 / 15(26.7 \%)$ & $1 / 1(100 \%)$ & $3 / 14(21.4 \%)$ & NA \\
\hline Non Cardiovascular & $768 / 3593(15.8 \%)$ & $23 / 313(7.3 \%)$ & $545 / 3280(16.6 \%)$ & $<0.0001^{* *}$ \\
\hline
\end{tabular}

AV, atrioventricular; TIA, Transient Ischemic Attack.

*P-values for among-group comparisons are from Kruskal-Wallis test.

**P-values for among-group comparisons are from Pearson's test.

***P-values for among-group comparisons are from Fisher's exact test. 
Table 4: Overall success rates in relationship with the type of atrial fibrillation: Italy vs other participating countries

\begin{tabular}{|l|c|c|c|c|}
\hline & Total & ITALY & Other countries & P value \\
\hline Paroxysmal AF & $1566 / 2085(75.1 \%)$ & $124 / 155(80.0 \%)$ & $1442 / 1930(74.7 \%)$ & $0.1432^{* *}$ \\
\hline Persistent AF & $587 / 828(70.9 \%)$ & $60 / 85(70.6 \%)$ & $527 / 743(70.9 \%)$ & $0.9478^{* *}$ \\
\hline Long Standing Persistent AF & $99 / 146(67.8 \%)$ & $4 / 6(66.7 \%)$ & $95 / 140(67.9 \%)$ & $1.0000^{* * *}$ \\
\hline Overall & $2252 / 3059(73.6 \%)$ & $188 / 246(76.4 \%)$ & $2064 / 2813(73.4 \%)$ & $0.2980^{* *}$ \\
\hline
\end{tabular}

No discontinuation of antiarrhythmic drugs was required by the protocol.

**P-values for among-group comparisons are from Pearson's test.

***P-values for among-group comparisons are from Fisher's exact test. 